\title{
Definition of obesity and current indications for obesity surgery
}

\author{
Aziz Sümer \\ Department of Visceral, Transplant, Bariatric and Metabolic Surgery, Yuzuncu Yil University Faculty of Medicine, Van, Turkey
}

\begin{abstract}
Rate of obesity has increased all over the world. Indications and contraindications for obesity surgery have not changed much; however, metabolic consequences of bariatric surgery have expanded some indications for obesity surgery in patients with comorbidities. The advancement and frequent usage of laparoscopic surgery have made bariatric surgical operations easier.
\end{abstract}

Keywords: Bariatric surgery; contraindications; indications; obesity; type 2 diabetes.

\section{Introduction}

As Buchwald says "to know what is new, one must know what is old". ${ }^{[1]}$ From this point of view, reviewing obesity history is a crucial step to understanding current definitions and indications. Bariatric surgery is a dynamic surgical field and changes have continued in recent years. ${ }^{[1,2]}$

The word "bariatric" comes from the Greek words "baros", meaning weight and "iatrikos", meaning the art of healing. This word has been used to define gastrointestinal operations for obese patients in order to help them lose weight. ${ }^{[3]}$

Humans have evolved from an active nomadic hunter-gatherer (consuming a high protein diet) to a settled farming species over the millennium. This sedentary life change is an important factor forobesity. ${ }^{[4]}$ While obesity was an icon representing power, heath, and wealth in ancient times, it is now accepted as a disease to be treated. ${ }^{[5]}$ In the 1950s, conservative treatment of morbid obesity was often unsuccessful. The first operation was performed to treat severe hyperlipidemia associated with obesity. History of bariatric surgery started with jejunoileal bypass by Varco. ${ }^{[1,4,6]}$ This operation limited absorption; however, it had some severe nutritional complications and liver failure postoperatively.

In 1966, Mason and Ito performed the first gastric bypass but the bile reflux e ophagitis was severe postoperatively. Roux-en-Y modification of the gastric bypass was developed by Griffinin 1977. ${ }^{[1,4]}$

Scopinaro developed and popularized the biliopancreatic diversion (BPD) procedure in the late 1970s. This procedure is mainly malabsorptive and still used by few su geons throughout the world $(<5 \%)_{\text {. }}^{[1,4]}$

In 1980, Mason described vertical banded gastroplasty (VBG) as a restrictive procedure causing excellent initial weight loss with low morbidity and mortality. It rapidly $\mathrm{b}$ 
came the most commonly performed bariatric operation in the United States during the 1980s. ${ }^{[1,4,7]}$

Afterwards, gastric banding was defined by Wilkinson and Pelosoin 1978, duodenal switch by Marceau in 1993, mini bypass by Rutledge in 2001, laparoscopic sleeve gastrectomy as the first step of a two-staged procedure for high-risk patients by Regan et al. in 2003, SADI-S by Sánchez-Pernaute and Torres in 2007, and gastric plication by Talebpour in 2007. ${ }^{[1,8-15]}$

There have been two major changes in the bariatric field recently. Firstly, laparoscopic development has increased the number of laparoscopic bariatric operations and made them easier than they were before. Secondly, nowadays, the concept of bariatric surgery is covering the ability of surgical therapy to treat the metabolic consequences of obesity more than obesity itself. ${ }^{[2,8,16-18]}$ Bariatric and metabolic surgery are proven therapies for obesity and its comorbidities. With bariatric surgery, not only the resolution or improvements of co-morbidities such as diabetes, hypertension, hyperlipidemia, obstructive sleep apnea, gastroesophageal reflux, and pseudo tumor cerebri occur, but also the prevalence of development of some type of cancers like breast and colon cancers decrease. Furthermore, bariatric surgery improves overall quality of life and causes long- term survival. ${ }^{[19,20]}$

\section{Definition}

Accepting and understanding obesity as a problem is the first step to dealing with it. Obesity has morbidity and mortality risks and it is a severe chronic disease consisting complex genetics and environmental causes. The term morbid applies to obesity in order to explain serious, progressive, and debilitating disease. ${ }^{[4,6]}$

According to the World Health Organization (WHO), obesity and overweight are defined abnormal or excessive fat accumulation that may impair health. ${ }^{[2]]}$ The imbalance between excess calorie intake and relatively less energy expenditure causes obesity. ${ }_{.}^{[21,22]}$ Obesity is a growing medical and socioeconomic problem, which WHO defined as the epidemic disease of the new age world called globosity. ${ }^{[17,23]}$

\section{Prevalence}

Obesity is a worldwide epidemic that currently affects both developed and developing countries. Obesity is the second leading cause of preventable death in the world.
[17,24] According to WHO, 1.7 billion adults, 20 years and older, were overweight or obese in 2008. 200 million men and nearly 300 million women were obese. Studies have shown that in the United States, United Kingdom and Australia, the prevalence of obesity in adults has doubled in the last 25 years. Obesity prevalence in Europe ranges between 40 and $60 \%{ }^{[1,12,17,20,21,25-29]}$

Obesity prevalence has increased over the last 20 years in the United States of America and currently ranks second in the world. Nearly two thirds of Americans are overweight or obese and almost 5\% are morbidly obese. In 2008, there were more than nine million morbidly obese Americans needing help. ${ }^{[1,30]}$

As similar in 2011 and 2012, 63\% of Australian adults had a body mass index (BMI) in either the overweight or the obese category. Being overweight was more prevalent among males than females ( $42 \%$ vs. $35 \%$ ) and obesity prevalence was similar among males and females $(28 \%){ }^{[6,31]}$

Obesity prevalence in Turkey is almost the same as the prevalence in developed western countries. According to apreliminary study report called "Nutrition and Health Research of Turkey" conducted by the Ministry of Health, obesity prevalence in Turkey is $20.5 \%$ among males and $41 \%$ among females. The total rate of overweight and obese is $64.9 \%$ and rate of morbidly obese is $2.9 \%$ in Turkey. ${ }^{[32]}$

The image of obesity among adolescents is the same as adults. Obesity prevalence has also increased among adolescents. The rate of extremely obese (defined as BMI $\geq 99^{\text {th }}$ percentile) is $4 \%$ among adolescents. ${ }^{[33]}$ The prevalence of obesity among adolescents has reached $35.8 \%$ in Latin America, 18.3\% in England, and 16, 5\% in the U.S. In our country, the prevalence is $8.2 \% \cdot{ }^{[32,34]}$

Prevalence of type 2 diabetes (T2DM) has risen is parallel to the increasing prevalence of obesity. In 2011, an estimated 366 million people had diabetes and this number will have reached to 522 million by 2030. ${ }^{[35]}$

Overweight and obesity are the problems of our generation. The number of bariatric surgical procedures performed worldwide has increased by $761 \%$ over the last decade. ${ }^{[6,23]}$ The dispersion of obesity in the world is shown in Figure 1 and in Figure 2 in Turkey.

\section{Classification of Obesity}

Some measures are used to classify obesity. Body mass 


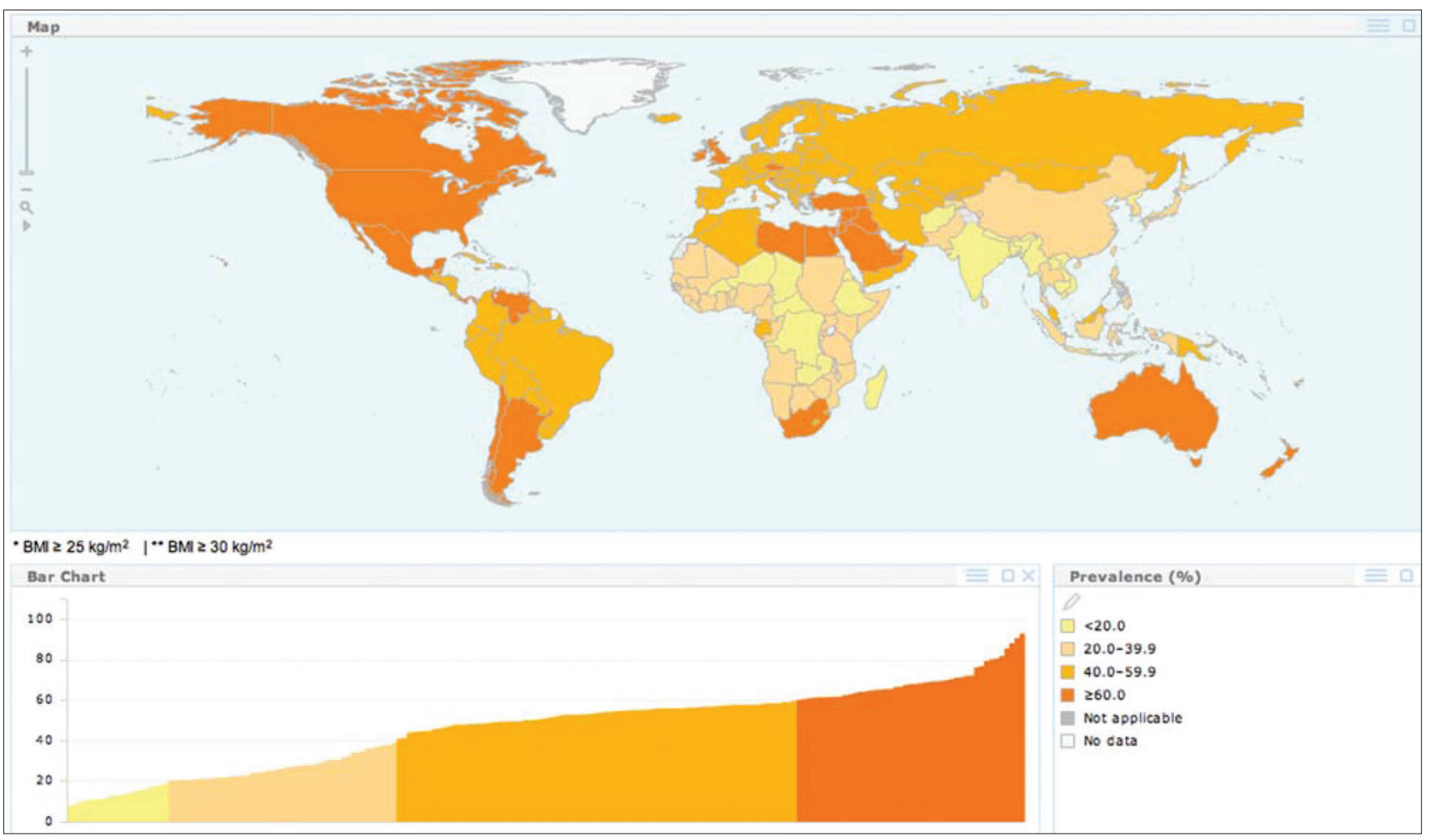

Figure 1. Dispersion of obesity in the World (This fi gure was taken from http://www.who.int/gho/ncd/risk_factors/ overweight/en).

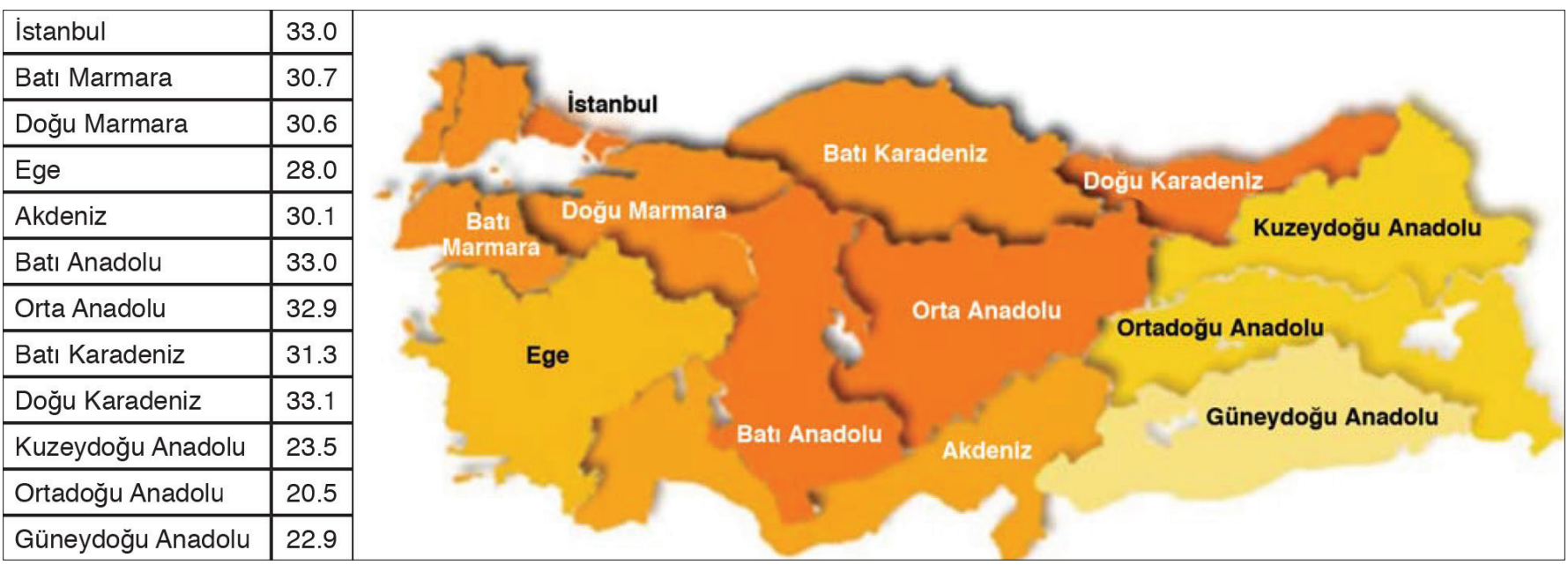

Figure 2. Dispersion of obesity in Turkey (This fi gure was taken from http://beslenme.gov.tr/index. php?lang=tr\&page $=40$ ).

index is the most commonly used measure. Body mass index is calculated as body weight in kilograms divided by height in meters squared $\left(\mathrm{kg} / \mathrm{m}^{2}\right)$. Patients are classified as overweight, obese, severe obese, and morbidly obese. In adults, desirable BMI is between 18.5 to $25 \mathrm{~kg} / \mathrm{m}^{2}$ and overweight is between 25 and $30 \mathrm{~kg} / \mathrm{m}^{2}$. A BMI of 30 is equivalent to a weight of $97.5 \mathrm{~kg}$ in a person who is $1.80 \mathrm{~m}$ tall or a weight of $77 \mathrm{~kg}$ in a person who is $1.60 \mathrm{~m}$ tall. Obesity is defined over a BMI of $30 \mathrm{~kg} / \mathrm{m}^{2}$. Obesity is classified into three categories including class I: $30-35 \mathrm{~kg} / \mathrm{m}^{2}$, class II: $35-40 \mathrm{~kg} / \mathrm{m}^{2}$, and class III: $\geq 40 \mathrm{~kg} / \mathrm{m}^{2}$. Class III obesity is known as morbid obesity. ${ }^{[17,20,25-28]}$

Later, some more definitions have been added to this classification system. BMI more than 50 is defined super morbid obese and greater than 60 is defined super morbid obesity. ${ }^{[2,16,36-38]}$

Definitions of overweight and obesity are based on the cri- 
teria coming from studies involving the populations of European origin. ${ }^{[25]}$ Nevertheless, different populations have different associations between BMI, percentage of body fat, and health risk. ${ }^{[20]}$ Other methods to classify obesity include waist circumference and central and peripheral fat mass. ${ }^{[16]}$

\section{Indications for Obesity Surgery}

Indications for obesity surgery were firstly described by the NIH Consensus Conference of 1991 and there have been a few changes so far. The guidelines have generally focused on bodymass index (BMI) and the presence of comorbidities. ${ }^{[2,19,26,39]}$ Traditional indications defining the NIH consensus conference for obesity surgery included the patients whose BMI exceeds $40 \mathrm{~kg} / \mathrm{m}^{2}$ or $35 \mathrm{~kg} /$ $\mathrm{m}^{2}$ in the presence of comorbidities (such as metabolic disorders, cardio respiratory disease, severe joint disease, obesityrelated severe psychological problems) and when conservative treatment has failed. The term "when conservative treatment has failed" is newly replaced by the term "when conservative treatment has exhausted", meaning the treatment goal of 10 to $20 \%$ weight loss in a patient whose BMI is 35 to $40 \mathrm{~kg} / \mathrm{m}^{2}$ or 10 to $30 \%$ in a patient whose BMI exceeds $40 \mathrm{~kg} / \mathrm{m}^{2}$ cannot be reached and maintained in 6 to 12 months of treatment. ${ }^{[1,23]}$

According to Interdisciplinary European Guidelines on Metabolic and Bariatric Surgery published in 2013 by Fried et al., indications for obesity surgery cover extra criteria. ${ }^{[17]}$ In addition to classical NIH's indications, BMI $\geq 40$ $\mathrm{kg} / \mathrm{m}^{2}$ and BMI $35-40 \mathrm{~kg} / \mathrm{m}^{2}$ with co-morbidities, the other extra indication is the current BMI of the patient being below than required for surgery due to weight loss as a result of intensified treatment before surgery.

BMI alone is not an ideal parameter for defining indications for bariatric surgery in patients who have T2DM. Due to the fact that definitions of overweight and obesity are based on the criteria of European origin, BMI threshold should be adjusted by 2.5 for individuals of Asian origin. ${ }^{[17,25]}$

The American Society for Bariatric and Metabolic Surgery (ASMBS), the American Association of Clinical Endocrinologists (AACE), and the International Diabetes Federation (IDF) have agreed on considering bariatric and metabolic surgery in patients with a BMI of $30-34.9 \mathrm{~kg} / \mathrm{m}^{2}$ and diabetes or metabolic syndrome. ${ }^{[40-42]}$ The U.S. Food and Drug Administration (FDA) approved the Lap-Band TM for patients with a BMI of $30-34.9 \mathrm{~kg} / \mathrm{m}^{2}$ and obesity-related co-morbidities. ${ }^{[16,19,43]}$
According to IFSO-APC Consensus Statements in 2011, surgical approach may be considered as a non-primary alternative to treat inadequately controlled T2DM or metabolic syndrome for suitable Asian candidates with a BMI $\geq 27.5 \mathrm{~kg} / \mathrm{m} \cdot$. $^{[2,25]}$

Indication for obesity surgery in adolescents and children could be considered in centers with extensive experience of such treatment in adults and in ones that are able to offer a true multidisciplinary approach, involving pediatric surgeon, dietician and psychological management team. ${ }^{[17]}$

There are two concepts related to the indications in adolescents. On the one hand, obesity surgery can be considered if the patient has a BMI $>40 \mathrm{~kg} / \mathrm{m}^{2}$ (or $99.5^{\text {th }}$ percentile for respective age) and at least one co-morbidity or BMI $\geq 50 \mathrm{~kg} / \mathrm{m}^{2}$ with or without major co-morbidities. ${ }^{[17,24]}$ On the other hand, according to the guideline of Australia and New Zealand, indications for obesity surgery among adolescents are same as adult indications comprising a BMI $\geq 40 \mathrm{~kg} / \mathrm{m}^{2}$ and $\mathrm{BMI} 35-40 \mathrm{~kg} / \mathrm{m}^{2}$ with the presence of severe obesity related complications. ${ }^{[19,44]}$ The NIH statement noted that the surgical candidate should be evaluated by a multidisciplinary team consistingmedical, surgical, psychiatric, and nutritional specialists. The advantages and disadvantages of all treatment options should be discussed with the patient and/he should be involved in the treatment. ${ }^{[19,26]}$

\section{Contraindications for Obesity Surgery}

There are few absolute contraindications for metabolic and obesity surgery and most of them are same as elective general surgeries', such as uncontrolled coagulopathy and contraindication to general anesthesia. ${ }^{[2,19]}$ Bariatric surgery should not be performed on patients with limited life expectancy due to end organ failure and metastatic or inoperable malignancies. In patients willing to get pregnant within 12 months or are pregnant, the operation should be deferred. ${ }^{[19]}$

European Guidelines on Metabolic and Bariatric Surgery stated that following situations are contraindications of bariatric and metabolic surgery: ${ }^{[17]}$ absence of a period of identifiable medical management, patient who is unable to participate in the prolonged medical follow-up, nonstabilized psychotic disorders, severe depression, personality and eating disorders, unless specifically advised by a psychiatrist experienced in obesity, and alcohol abuse and/or drug dependencies. Furthermore, bariatric surgery may be contraindicated for patients who are un- 
able to care for themselves and have nosocial support. For diabetes, the specific exclusion criteria for metabolic surgery are secondary diabetes and antibodies positivity (anti-GAD or anti-ICA) or C-peptide $<1 \mathrm{ng} / \mathrm{mL}$ or being unresponsive to mixed meal challenge.

Relative contraindications for obesity and metabolic surgery are patients' impaired intellectual capacity, malignant hyperphagia and resistance to life changing modifications in post bariatric term. ${ }^{[19]}$

Genetic syndrome like Prader-Willi was a contraindication before. However, some case reports have shown that bariatric surgery among this population can be effective. ${ }^{[17,19,45]}$ There is a need to carry out more studies to show the effectiveness of bariatric surgery among this population.

\section{Specific Situations}

Although the prevalence of morbid obesity has been rising among elderly patients recently, the majority of operated patients are younger than 50 years of age. In the UK, the mean age of patients undergoing bariatric surgery is 4043 years. Due to the perceived complication risks and poor outcomes of surgery, most bariatric surgeons are frightened to propose bariatric surgery to older patients. ${ }^{[46]}$

Although age limit is shown by European Guidelines on Metabolic and Bariatric Surgery as between 18 to 60 years of age in adults, no higher age limit for bariatric surgery was recommended in the NIH conference in 1991. ${ }^{[1719,26]}$ At the time of publication, there was insufficient data to make a recommendation for or against surgery for adolescent population. ${ }^{[19]}$

Busetto et al. have not found any differences between the age groups of 60-69 and 70-79 years in terms of an improvement in weight loss and co-morbidities. ${ }^{[47]}$ In light of the current studies, metabolic and bariatric surgery should be performed on selected patients aged 65 and older. ${ }^{[17,19,46]}$

Baur et al. recommenda minimum of 15 years of age for adolescents. Since the effects of bariatric surgery is unknown among preadolescents, it is not recommended for this group. ${ }^{[19,44]}$

\section{Psychiatric Illness}

It has been shown that around $40 \%$ of all bariatric surgery patients have at least one psychiatric diagnosis. ${ }^{[48]}$ Presence of psychopathology, including eating disor- ders, is not a contraindication of bariatric and metabolic surgery. Some successful outcomes have been obtained among patients having major depressive disorders, bipolar disorders, stable schizophrenia, and binge eating. Preoperative psychiatric evaluation is mandatory in order to maintain therapy for stable disorders. For patients with active psychoses or recent hospitalization, suicidal idea, and recent suicidal attempt, surgery should be delayed or postponed. ${ }^{[19,48]}$

\section{Cirrhosis}

Obesity is associated with fatty liver disease. The prevalence of non-alcoholic fatty liver disease (NAFLD) and non-alcoholic steatohepatitis (NASH) range from $84-96 \%$ and $25-55 \%$, respectively, among obese patients. ${ }^{[49]}$ The incidence of unexpected cirrhosis is $2 \%$ during bariatric surgery. ${ }^{[19,49]}$

Patients with known cirrhosis should be carefully evaluated preoperatively. The cause of cirrhosis should be determined and hepatic function should be assessed by Child-Pugh classification. The presence of portal hypertension should be evaluated in addition to the regular preoperative workup for bariatric patients. If evidence of portal hypertension is detected during surgery, the operation should be stopped. ${ }^{[1,49,50]}$

It has been shown that weight loss improves the histological findings of steatosis and steatohepatitis. Surgery may be safely conducted in stable cirrhotic patients. This type of challenging operations should be performed in selected tertiary centers experienced in liver transplant. ${ }^{[19,49]}$

\section{HIV Infection}

Because of acquired immunodeficiency due to weight loss after bariatric surgery, HIV positivity was thought as a contraindication for bariatric operations. Modern antiretroviral therapy has dramatically improved prognosis of the disease and extended life expectancy. Two years after antiretroviral therapy, lipodystrophy causes overweight and obesity up to $20 \%$ in the HIV population. Although there is debate about bariatric surgery for HIV positive group, there have been reported case series demonstrating safety and efficacy of metabolic and bariatric surgery with stable HIV infection. ${ }^{[1,50]}$

\section{Non-Ambulatory Patients}

Some guidelines and programs accept non-ambulatory as 
a contraindication of bariatric surgery. However, obesity has aggravated co-morbidities among non-ambulatory patients. The profit of bariatric surgery by inducing weight loss is considered for this group. In selected non-ambulatory patients, bariatric and metabolic surgery should be performed in atertiary center. ${ }^{[19]}$

\section{Conclusion}

Although the number of bariatric operations has increased in years due to the usage of laparoscopic techniques, unfortunately, still only $1 \%$ of obese patients can be treated. ${ }^{[8,22]}$ The indications of metabolic and obesity surgery should be based on not only BMI but also on metabolic comorbidities With the development of laparoscopic surgery, bariatric surgery has gained popularity and the indications of bariatric surgery have extended.

\section{References}

1. Buchwald H. Overview of bariatric surgery. J Am Coll Surg 2002;194:367-75.

2. Schauer PR, Schirmer BS. The surgical management of obesity. In: Brunicardi F, Andersen D, Billiar T, Dunn D, Hunter JG, Matthews J, et al. editors. Schwartz's Principles of Surgery. 10th ed. New York: McGraw-Hill; 2015: p. 1099-136.

3. Pinkney J, Kerrigan D. Current status of bariatric surgery in the treatment of type 2 diabetes. Obes Rev 2004;5:69-78.

4. Deitel M. A brief history of the surgery for obesity to the present, with an overview of nutritional implications. J Am Coll Nutr 2013;32:136-42.

5. Satman I, Yumuk VD, Erem C, Bahçeci M, Araz M, Sönmez A, et al. Obezite Tanı ve Tedavi Klavuzu. 1st ed. Ankara: Miki Matbaacılık; 2014.

6. O'Brien PE. Bariatric surgery: mechanisms, indications and outcomes. J Gastroenterol Hepatol 2010;25:1358-65.

7. Marceau P, Biron S, Bourque RA, Potvin M, Hould FS, Simard S. Biliopancreatic Diversion with a New Type of Gastrectomy. Obes Surg 1993;3:29-35.

8. Lo Menzo E, Szomstein S, Rosenthal RJ. Changing trends in bariatric surgery. Scand J Surg 2015;104:18-23.

9. Gluck B, Movitz B, Jansma S, Gluck J, Laskowski K. Laparoscopic sleeve gastrectomy is a safe and effective bariatric procedure for the lower BMI $(35.0-43.0 \mathrm{~kg} / \mathrm{m} 2)$ population. Obes Surg 2011;21:1168-71.

10. Regan JP, Inabnet WB, Gagner M, Pomp A. Early experience with two-stage laparoscopic Roux-en-Y gastric bypass as an alternative in the super-super obese patient. Obes Surg 2003;13:861-4.

11. Cottam D, Qureshi FG, Mattar SG, Sharma S, Holover S, Bonanomi G, et al. Laparoscopic sleeve gastrectomy as an initial weight-loss procedure for high-risk patients with morbid obesity. Surg Endosc 2006;20:859-63.
12. Bellows CF, Gauthier JM, Webber LS. Bariatric aftercare and outcomes in the Medicaid population following sleeve gastrectomy. JSLS 2014;18. pii: e2014.00280.

13. Rutledge R. The mini-gastric bypass: experience with the first 1,274 cases. Obes Surg 2001;11:276-80.

14. Sánchez-Pernaute $A$, Rubio Herrera MA, Pérez-Aguirre $E$, García Pérez JC, Cabrerizo L, Díez Valladares L, et al. Proximal duodenal-ileal end-to-side bypass with sleeve gastrectomy: proposed technique. Obes Surg 2007;17:1614-8.

15. Talebpour M, Amoli BS. Laparoscopic total gastric vertical plication in morbid obesity. J Laparoendosc Adv Surg Tech A 2007; 17:793-8.

16. Dixon JB, Zimmet P, Alberti KG, Rubino F; International Diabetes Federation Taskforce on Epidemiology and Prevention. Bariatric surgery: an IDF statement for obese Type 2 diabetes. Arq Bras Endocrinol Metabol 2011;55:367-82.

17. Fried M, Yumuk V, Oppert JM, Scopinaro N, Torres AJ, Weiner $\mathrm{R}$, et al; European Association for the Study of Obesity; International Federation for the Surgery of Obesity - European Chapter. Interdisciplinary European Guidelines on metabolic and bariatric surgery. Obes Facts 2013;6:449-68.

18. Sundbom M. Laparoscopic revolution in bariatric surgery. World J Gastroenterol 2014;20:15135-43.

19. Provost DA. Indications and contraindications for bariatric surgery. In: Nguyen NT, Blackstone RB, Morton JM, Ponce J, Rosenthal RJ, editors. The ASMBS Textbook of Bariatric Surgery. Volume 1: Bariatric Surgery. 1st ed. New York: Springer Science, Business Media; 2015: p. 73-6.

20. Colquitt JL, Pickett K, Loveman E, Frampton GK. Surgery for weight loss in adults. Cochrane Database Syst Rev 2014; CD003641.

21. World Health Organization (WHO). Available at: http://www. who.int/gho/ncd/risk_factors/overweight/en/. Accessed Dec 30, 2014

22. Alverdy JC, Prachand V, Flanagan B, Thistlethwaite WA, Siegler $M$, Garfinkel $M$, et al. Bariatric surgery: a history of empiricism, a future in science. J Gastrointest Surg 2009;13:465-77.

23. Runkel N, Colombo-Benkmann M, Hüttl TP, Tigges $H$, Mann O, Sauerland S. Bariatric surgery. Dtsch Arztebl Int 2011;108:341-6.

24. Xanthakos SA. Bariatric surgery for extreme adolescent obesity: indications, outcomes, and physiologic effects on the gut-brain axis. Pathophysiology 2008;15:135-46.

25. Kasama K, Mui W, Lee WJ, Lakdawala M, Naitoh T, Seki Y, et al. IFSO-APC consensus statements 2011. Obes Surg 2012;22:677-84.

26. Brolin RE. Update: NIH consensus conference. Gastrointestinal surgery for severe obesity. Nutrition 1996;12:403-4.

27. Kushner RF, Herrington $H$. Surgery for severe obesity. In: Coulston A, Boushey C, Ferruzi M, editors. Nutrition in the Prevention and Treatment of Disease. 3rd ed. San Diego, San Francisco: Academic Press; 2013: p. 465-78.

28. Kissane NA, Pratt JS. Medical and surgical treatment of obesity. Best Pract Res Clin Anaesthesiol 2011;25:11-25. 
29. Fitzgerald DA, Baur L. Bariatric surgery for severely obese adolescents. Paediatr Respir Rev 2014;15:227-30.

30. SAGES Guidelines Committee. SAGES guideline for clinical application of laparoscopic bariatric surgery. Surg Obes Relat Dis 2009;5:387-405.

31. Clinical Practice Guidelines for the Management of Overweight and Obesity in Adults, Adolescents and Children in Australia (2013). Available at: htps://www.nhmrc.gov.au/_ files_nhmrc/publications/attachments/n57_obesity_guidelines_131204_0.pdf. Accessed Dec 30, 2014.

32. Obezite, Diyabet ve Metabolik Hastalıklar Daire Başkanlığı. Available at: http: //beslenme.gov.tr/index. php?lang=tr\&page=40. Accessed Dec 30, 2014.

33. Freedman DS, Mei Z, Srinivasan SR, Berenson GS, Dietz WH. Cardiovascular risk factors and excess adiposity among overweight children and adolescents: the Bogalusa Heart Study. J Pediatr 2007;150:12-7.

34. Beamish AJ, Johansson SE, Olbers T. Bariatric surgery in adolescents: what do we know so far? Scand J Surg 2015;104:24-32.

35. Dixon JB, le Roux CW, Rubino F, Zimmet P. Bariatric surgery for type 2 diabetes. Lancet 2012;379:2300-11.

36. Sundbom M. Open duodenal switch for treatment of super obesity-surgical technique. Scand J Surg 2015;104:54-6.

37. Renquist K. Obesity classification. Obes Surg 1998;8:480.

38. García-Caballero M, Reyes-Ortiz A, García M, Martínez-Moreno JM, Toval-Mata JA. Super obese behave different from simple and morbid obese patients in the changes of body composition after tailored one anastomosis gastric bypass (BAGUA). Nutr Hosp 2014;29:1013-9.

39. Pucci A, Finer N. New medications for treatment of obesity: metabolic and cardiovascular effects. Can J Cardiol 2015;31:142-52.

40. ASMBS Clinical Issues Committee. Bariatric surgery in class I obesity (body mass index $30-35 \mathrm{~kg} / \mathrm{m}^{2}$ ). Surg Obes Relat Dis 2013;9:e1-10.
41. Mechanick JI, Youdim A, Jones DB, Timothy Garvey W, Hurley $\mathrm{DL}$, Molly McMahon $\mathrm{M}$, et al. Clinical practice guidelines for the perioperative nutritional, metabolic, and nonsurgical support of the bariatric surgery patient--2013 update: cosponsored by American Association of Clinical Endocrinologists, the Obesity Society, and American Society for Metabolic \& Bariatric Surgery. Surg Obes Relat Dis 2013;9:159-91.

42. Dixon JB, Zimmet P, Alberti KG, Rubino F; International Diabetes Federation Taskforce on Epidemiology and Prevention. Bariatric surgery: an IDF statement for obese Type 2 diabetes. Surg Obes Relat Dis 2011;7:433-47.

43. Campos JM, Lins DC, Silva LB, Araujo-Junior JG, Zeve JL, Ferraz ÁA. Metabolic surgery, weight regain and diabetes re-emergence. Arq Bras Cir Dig 2013;26 Suppl 1:57-62.

44. Baur LA, Fitzgerald DA. Recommendations for bariatric surgery in adolescents in Australia and New Zealand. J Paediatr Child Health 2010;46:704-7.

45. Musella M, Milone $M$, Leongito $M$, Maietta $\mathrm{P}$, Bianco $\mathrm{P}$, Pisapia A. The mini-gastric bypass in the management of morbid obesity in Prader-Willi syndrome: a viable option? J Invest Surg 2014;27:102-5.

46. Lynch J, Belgaumkar A. Bariatric surgery is effective and safe in patients over 55: a systematic review and meta-analysis. Obes Surg 2012;22:1507-16.

47. Busetto L, Angrisani L, Basso N, Favretti F, Furbetta F, Lorenzo M; Italian Group for Lap-Band. Safety and efficacy of laparoscopic adjustable gastric banding in the elderly. Obesity 2008;16:334-8.

48. Yen YC, Huang CK, Tai CM. Psychiatric aspects of bariatric surgery. Curr Opin Psychiatry 2014;27:374-9.

49. Shimizu H, Phuong V, Maia M, Kroh M, Chand B, Schauer PR, et al. Bariatric surgery in patients with liver cirrhosis. Surg Obes Relat Dis 2013;9:1-6.

50. Flancbaum L, Drake V, Colarusso T, Belsley S. Initial experience with bariatric surgery in asymptomatic human immunodeficiency virus-infected patients. Surg Obes Relat Dis 2005;1:73-6. 